Review Article

\title{
Relationships between chromatin remodeling and DNA damage repair induced by 8-methoxypsoralen and UVA in yeast Saccharomyces cerevisiae
}

\author{
Lavínia Almeida Cruz ${ }^{1}$, Temenouga Nikolova Guecheva², Diego Bonato ${ }^{1,3}$ \\ and João Antônio Pêgas Henriques ${ }^{1,2,4}$ \\ IPrograma de Pós-Gradução em Genética e Biologia Molecular, Departamento de Genética, \\ Universidade Federal do Rio Grande do Sul, Porto Alegre, RS, Brazil. \\ ${ }^{2}$ Laboratório de Genotoxicidade, Instituto Royal, Centro de Biotecnologia, \\ Universidade Federal do Rio Grande do Sul, Porto Alegre, RS, Brazil. \\ ${ }^{3}$ Deparamento de Biologia Molecular, Centro de Biotecnologia, \\ Universidade Federal do Rio Grande do Sul, Porto Alegre, RS, Brazil. \\ ${ }^{4}$ Instituto de Biotecnologia, Universidade de Caxias do Sul, Caxias do Sul, RS, Brazil.
}

\begin{abstract}
Eukaryotic cells have developed mechanisms to prevent genomic instability, such as DNA damage detection and repair, control of cell cycle progression and cell death induction. The bifunctional compound furocumarin 8-methoxypsoralen (8-MOP) is widely used in the treatment of various inflammatory skin diseases. In this review, we summarize recent data about the role of chromatin remodeling in the repair of DNA damage induced by treatment with 8-methoxypsoralen plus UVA (8-MOP+UVA), focusing on repair proteins in budding yeast Saccharomyces cerevisiae, an established model system for studying DNA repair pathways. The interstrand crosslinks (ICL) formed by the 8-MOP+UVA treatment are detrimental lesions that can block transcription and replication, leading to cell death if not repaired. Current data show the involvement of different pathways in ICL processing, such as nucleotide excision repair (NER), base excision repair (BER), translesion repair (TLS) and double-strand break repair. 8-MOP+UVA treatment in yeast enhances the expression of genes involved in the DNA damage response, double strand break repair by homologous replication, as well as genes related to cell cycle regulation. Moreover, alterations in the expression of subtelomeric genes and genes related to chromatin remodeling are consistent with structural modifications of chromatin relevant to DNA repair. Taken together, these findings indicate a specific profile in 8-MOP+UVA responses related to chromatin remodeling and DNA repair.
\end{abstract}

Keywords: DNA repair, psoralen, chromatin remodeling, histones, DNA interstrand cross-links.

\section{Introduction}

Eukaryotic cells have developed mechanisms to prevent genomic instability, such as DNA damage detection and repair, control of cell cycle progression and cell death induction (Lobrich and Jeggo, 2007). Recent studies have revealed the importance of histone modification in the recruitment of proteins involved in the cellular response to DNA damage (Escargueil et al., 2008; van Attikum and Gasser, 2009; Lu et al., 2009). In this review, we compile recent data about the role of chromatin remodeling in the repair of DNA damage induced by treatment with 8-methoxypsoralen plus UVA (8-MOP+UVA), focusing on the re-

Send correspondence to João Antonio Pêgas Henriques. Centro de Biotecnologia, Universidade Federal do Rio Grande do Sul, Av. Bento Gonçalves 9500, Caixa Postal 15005, 91501-970 Porto Alegre, RS, Brazil. E-mail: pegas@ cbiot.ufrgs.br. spective repair proteins in budding yeast Saccharomyces cerevisiae, a proven excellent model system for studying DNA repair pathways (Henriques et al., 1997; Noll et al., 2006).

\section{8-Methoxypsoralen: DNA Damage and Repair}

The bifunctional furocumarin 8-methoxypsoralen (8-MOP) is widely used in the treatment of various inflammatory skin diseases (Dardalhon et al., 2007). The cellular effects of 8-MOP are due to its ability to bind to pyrimidine bases in DNA upon UVA irradiation. This binding occurs in a specific and covalent manner, resulting in the formation of both monoadducts and interstrand cross-links (ICLs) (Brendel and Henriques, 2001; Brendel et al., 2003; Noll et al., 2006). ICL caused by 8-MOP has specific structural characteristics which distinguish them from ICLs caused by other alkylating agents such as nitrogen mustard, 
mitomycin $\mathrm{C}$, cisplatin, carmustine and malondialdehyde (reviewed by Guainazzi and Schärer, 2010). Moreover, the psoralen-induced ICL can block transcription and inhibit DNA replication, leading to cell death if not repaired (Lehoczky et al., 2007). Furthermore, due to the chemical stability of the cross-links and the facility of psoralen-DNA ICL synthesis, many studies have addressed DNA repair using psoralen ICL (Brendel et al., 2003; Noll et al., 2006 Vasquez, 2010; Le Breton et al., 2011).

The repair of ICL in S. cerevisiae is initiated by recognition of the lesion by the Nucleotide Excision Repair (NER, Rad4p/Rad23p) mechanism. Subsequently, Rad2p nicks one of the DNA strands at 3' to the ICL, while the Rad1p/Rad10p complex cleaves the same strand at 5' to the damage. The incised ICL is flipped out and the opposite strand serves as a template for the translesion polymerase machinery that has the ability to bypass the ICL. Next, cleavage occurs on the opposite strand to completely remove the ICL damage, leading to double strand breaks (DSBs), which then can be repaired by the homologous recombination machinery (reviewed by Wood, 2010). In this process, Pso3p/Rnr4p plays an important role in the regulation of translesion polymerase $\zeta$ in error-prone repair of psoralen ICL (Brendel et al., 2003). Curiously, genes involved in the NER pathway (RAD2, RAD16 and RAD23) and the post-replication repair (PRR) pathway (RAD18), which participates in the repair of 8-MOP+UVA lesions (Henriques and Moustacchi, 1981; Brendel and Henriques, 2001; Saffran et al., 2004), were not up-regulated by 8MOP+UVA treatment in yeast (Dardalhon et al., 2007).

It has been shown that DSBs, formed as repair intermediates of 8-MOP photo-additions in DNA, are preferentially located in intergenic regions, where the TATA boxes and/or transcription termination consensus sequences are also situated (Dardalhon et al., 1998). Furthermore it is known that during the chromatin photoreaction with psoralen, ICLs are preferentially made in the linker DNA between adjacent nucleosomes (Lucchini and Wellinger, 2001). Recently, Mace-Aime et al. (2010) showed that the base excision repair (BER) pathway can provide an alternative pathway for the repair of psoralen-DNA photoadducts in human cells by the DNA glycosylase NEIL1, which directly participates in the removal of ICLs.

More than 30 years ago, Henriques and Moustacchi (1980) isolated a new class of $S$. cerevisiae mutants sensitive to photo-activated psoralens, so-called pso mutants. One of the mutant proteins, Pso2p, was shown to participate in the repair of DSBs induced by DNA inter-strand cross-linking agents such as cisplatin, nitrogen mustard or photo-activated bi-functional psoralens. The molecular function of Pso2p in DNA repair has only partially been characterized, but yeast and mammalian cell line mutants for $\mathrm{PSO} 2$ show the same cellular responses as strains with defects in NHEJ, viz. sensitivity to ICLs and apoptosis. Pso2p/Snmlp is a member of the metallo- $\beta$-lactamase fam- ily of proteins, it has DNA 5'-exonuclease activity in vitro, and seems to have a specific role in repair of ICL (MaganaSchwencke et al., 1982; Brendel and Henriques, 2001; Bonatto et al., 2005).

Pso2p/Snm1 $\mathrm{p}$ can be directed to incised cross-links to resect repair intermediates, thus supplying substrates for downstream repair, such as translesion synthesis (TLS, by

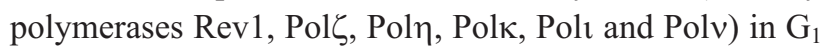
phase or homologous recombination (HR) in $\mathrm{S}-$ and $\mathrm{G}_{2-}$ phases (Figure 1) (Magana-Schwencke et al., 1982; Bonatto et al. 2005; Yan et al., 2010; Cattell et al., 2010). Pso2p/Snm1p also showed an overlapping role with the 5'-3' mismatch repair exonuclease Exo1 during HR repair of collapsed replication forks (Sarkar et al., 2006; Yan et al., 2010). Hazrati et al. (2008) suggested that hSnm1 A is a functional homologue of the yeast Pso2p/Snm1p. Although Pso2p/Snm1p binds to the 5'-phosphate moiety, present in both, DNA or RNA molecules, its activity on doublestranded substrates is very low (Hejna et al., 2007). Furthermore, Dudás et al. (2007) provided evidence that the function of Pso $2 \mathrm{p} / \mathrm{Snm} 1 \mathrm{p}$ in repair of ICL-associated DSB can be individual, without crosstalk with DSB repair machinery.

\section{DSB Damage Signaling: The Role of $\gamma-\mathrm{H} 2 \mathrm{~A}$}

One of the first responses triggered by the cells as a consequence of DSBs formed as intermediates during the

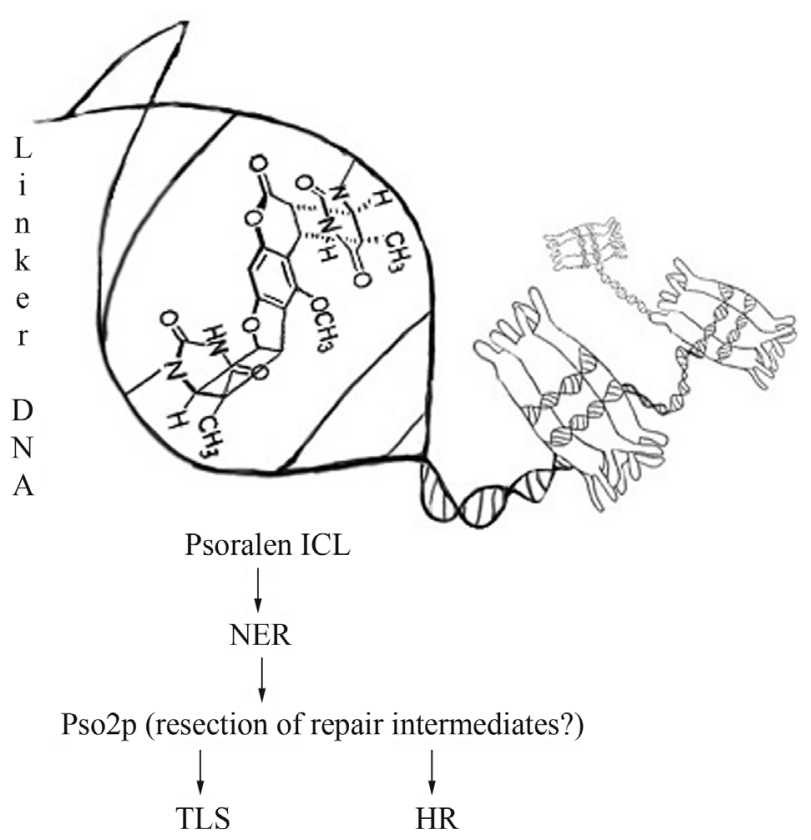

Figure 1 - Main pathways involved in the repair of 8-MOP+UVA induced ICL in yeast Saccharomyces cerevisiae. After treatment, ICL is formed preferentially in linker DNA between adjacent nucleosomes. Initially, psoralen ICL is recognized by NER machinery and subsequently incised from one of the DNA strands. Pso2p can be directed to incised cross-links in order to resect repair intermediates, thus supplying substrates for downstream repair such as translesion synthesis (TLS) in $\mathrm{G}_{1}$ phase or homologous recombination (HR) in $\mathrm{S}$ - and $\mathrm{G}_{2}$-phases. 
repair of 8-MOP/UVA induced ICL is the fast induction of $\mathrm{H} 2 \mathrm{AX}$ histone phosphorylation (in mammals at serine 139) surrounding the DSB site. This reaction is catalyzed by members of the phosphoinositide 3-kinase related protein kinase (PIKK) family (ATM, ATR and DNA-PK in mammalian cells or Tellp and Mec1p in yeast, Figure 2) (van Attikum and Gasser, 2005a). In response to DNA damage, $\mathrm{H} 2 \mathrm{~A}$ histone is also phosphorylated at serine 129 , located four residues from the carboxy terminus. The phosphorylated species, referred to as $\gamma-\mathrm{H} 2 \mathrm{~A}$ (or $\gamma-\mathrm{H} 2 \mathrm{AX}$ ), spreads up to $50 \mathrm{~kb}$ around the DSB (Gangaraju and Bartholomew, 2007). In addition, H2A serine 122 (or threonine 119 in mammals) was also shown to be involved in mediating cell survival after many kinds of DNA damage, but its function in repair is independent from that of S129 (Ataian and Krebs, 2006).

The formation of $\gamma-\mathrm{H} 2 \mathrm{~A}$ results in the recruitment of several chromatin remodeling complexes at the site of DNA damage promoting changes in chromatin structure, so that the repair factors can gain access to the lesion. After 8-MOP+UVA treatment, the accumulation of DNA damage repair proteins occurs in sub-nuclear foci called ionizing-radiation-induced foci (IRIF), and studies in mice show that the histone variant $\mathrm{H} 2 \mathrm{AX}$ is a core element in IRIF formation, although it is still unclear how proteins are actually recruited and retained as foci (van Attikum and Gasser, 2009). In yeast, mutations in H2A (Ser129) increase cell sensitivity to DNA-damaging agents and impair DSB repair. In mice, the mutation or deletion of H2AX impairs or abolishes the accumulation of DNA damage response proteins into IRIF, suggesting a role of $\gamma-\mathrm{H} 2 \mathrm{AX}$ as a key regulator of checkpoint signaling or repair itself (Celeste et al., 2002; Celeste et al., 2003). H2AX phosphorylation also recruits cohesin complexes to DSBs, which may explain the formation of a large domain of $\gamma-\mathrm{H} 2 \mathrm{AX}$-containing chro-

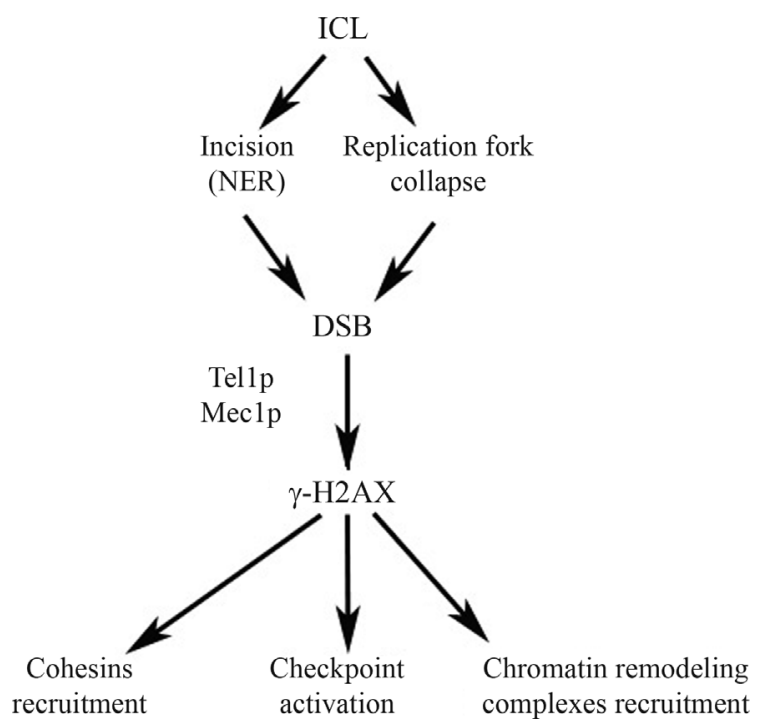

Figure 2 - DSB formation and $\gamma$-H2AX signaling following ICL formation. matin around DSBs. This prevents the loss of entire chromosome regions, as well as the progression of DNA breaks to chromosome breaks and translocations, keeping the DNA ends in close proximity for efficient repair (Altaf et al., 2007).

The DNA end-binding Mre11-Rad50-Nbs1 (MRN) complex, which is involved in recognition, signaling and repair of DSBs in mammalian cells, specifically binds to the $\gamma-\mathrm{H} 2 \mathrm{AX}$ by the Nbs 1 subunit. This interaction between Nbs1 and $\gamma-\mathrm{H} 2 \mathrm{AX}$ is required for retention of the MRN complex at the damaged site, although recent work has shown that the MRN complex can initiate DNA end resection and $\mathrm{HR}$ repair in an $\mathrm{H} 2 \mathrm{AX}$-independent pathway, which also starts ATM activation and cell cycle checkpoints (Yuan and Chen, 2010). Moreover, 53BP1 and its yeast homologs Saccharomyces cerevisiae Rad9p and Schizosaccharomyces pombe $\mathrm{Crb} 2 \mathrm{p}$ act as adaptor proteins between the sensing and effector kinases ATM and Chk1p, respectively, operating in the checkpoint response to DNA damage (Sweeney et al., 2005). 53BP1 also interacts with $\gamma-\mathrm{H} 2 \mathrm{AX}$ and depends on it for the checkpoint function (Altaf et al., 2007). Several studies have demonstrated the recruitment of chromatin remodeling complexes to DSBs by $\gamma-\mathrm{H} 2 \mathrm{AX}$. Indeed, in yeast, the $\gamma-\mathrm{H} 2 \mathrm{~A}$ binder list includes the histone acetyltransferase (HAT) NuA4, as well as the chromatin remodeling complex proteins INO80 and SWR1 (Table 1).

\section{Role of Chromatin Remodeling in DNA Damage Repair}

The recruitment of chromatin remodeling complexes to the site of DNA damage is essential to allow changes in chromatin structure, thus enabling the access and retention of repair factors to the lesion. It is worthy of note that changes in chromatin structure induced by the lesion itself also play a role in their recognition. The chromatin structure can suffer post-translational modifications of histones, incorporation of histone variants and ATP-dependent remodeling (Wang et al., 2009). The emerging concept is "access-repair-restore", in which changes in chromatin structure modulate: a) the access of repair factors to the damaged site, $b$ ) their retention until the end of the repair process, and c) the restoration of chromatin to its initial state. 8-MOP/UVA treatment in yeast enhances the expression of genes involved in the DNA damage response ( $R N R 2, D U N 1)$, in DSB repair by HR (RAD54, RAD51) as well as genes of the Mec1p/Rad53p kinase signaling cascade (Dardalhon et al., 2007). Other induced genes are NSE1 (encoding a protein component of the SMC5 SMC6complex), PAK1 (encoding an upstream kinase for the SNF1 complex), YRF1-2 (a helicase that is highly expressed in mutants lacking the telomerase component $T L C 1$ ), CDC45 (encoding a DNA replication initiation factor), ESC8 (encoding a protein involved in telomeric and 
Table 1 - Summary of the main activities of chromatin remodeling in yeast.

\begin{tabular}{ll}
\hline Chromatin remodeler & Main activities \\
\hline NuA4 complex & $\begin{array}{l}\text { Histone acetyltransferase acetylates H4 and } \\
\text { H2A histones, plays an important role in } \\
\text { DNA repair and interacts with } \gamma \text {-H2AX }\end{array}$ \\
SWR1 complex & $\begin{array}{l}\text { Helicase modulates the replacement of } \\
\text { histone H2A with HTZ (or H2AZ) }\end{array}$ \\
RSC complex & $\begin{array}{l}\text { Member of SWI/SNF class of remodelers. } \\
\text { Acts in transcriptional activation and repres- } \\
\text { sion, maintenance of cell viability and plays a } \\
\text { role in DSB repair }\end{array}$ \\
& $\begin{array}{l}\text { Nucleosome remodeling complex with } \\
\text { ATP-dependent activity, acts in gene tran- } \\
\text { scription and DSB repair }\end{array}$ \\
SWI/SNF complex & $\begin{array}{l}\text { ATPase with chromatin remodeling activity } \\
\text { and 3' to 5' DNA helicase activity in vitro }\end{array}$ \\
INO80 complex & $\begin{array}{l}\text { Histone deacetylase complex that regulates } \\
\text { gene transcription and silencing } \\
\text { DNA-dependent ATPase, stimulates strand } \\
\text { Sin3/Rpd3 complex } \\
\text { of DSBs }\end{array}$ \\
Rdh54 & Nucleossomal histone H3K79 methylase \\
\hline Dot1 &
\end{tabular}

mating-type locus silencing) and genes related to cell cycle regulation, including DUN1, SPO2, CTF19 and CDC27 (Dardalhon et al., 2007). In this scenario, we proposed a model whereby Pso2p would act on DNA hairpin substrates induced by ICLs during DNA replication, where the potential endonucleolytic function of Pso2p would be activated via Pak1p-induced phosphorylation (Brendel et al., 2003, Bonatto et al., 2005).

Furthermore, the induction of $Y R F 1-2$ and other subtelomeric genes, such as YFL061W, YFL065C and $Y F L 066 C$ is consistent with the need for changes in chromatin structure to allow repair of DNA damage after treatment with 8-MOP+UVA (Dardalhon et al., 2007). On the other hand, the repression of genes related to chromatin remodeling by treatment with $8-\mathrm{MOP}+\mathrm{UVA}$, such as RPD3 (encoding a histone deacetylase), IOC4 (implicated in chromatin remodeling) and the histone genes HTA1, HTA2 and HTB2 may also result in structural modifications of chromatin, relevant to DNA repair.

In general terms, DSB repair is related to local changes in chromatin structure, such as histone modifications, chromatin remodeling and nucleosome disruption (Osley et al., 2007). The NuA4 complex, which interacts with $\gamma$ $\mathrm{H} 2 \mathrm{AX}$ via its Arp4p subunit, is the first complex that appears at the break site (van Attikum and Gasser, 2009). The presence of NuA4 at the DSB site promotes the recruitment of DNA repair factors and of other chromatin modifying complexes, like SWR1-C and INO80 (Figure 3), perhaps by increasing accessibility to chromatin structure promoted by $\mathrm{H} 4$ acetylation (Altaf et al., 2007). In addition, the $\mathrm{H} 2 \mathrm{~A} . \mathrm{Z}$ acetylation by NuA4 may promote the replacement of H2A with $\gamma-\mathrm{H} 2 \mathrm{~A}$, in an SWR1-dependent manner, controlling the ratio of these two forms of $\mathrm{H} 2 \mathrm{~A}$ around the DSB site. This affects a phenomenon called checkpoint adaptation (Osley et al. 2007), in which cells can escape an extended checkpoint arrest and re-enter the cell cycle even with unrepaired DSBs (Papamichos-Chronakis et al., 2006; Osley et al., 2007).

A great deal of evidence connects INO80-dependent chromatin remodeling to DSB repair (reviewed by van Attikum and Gasser, 2009). The INO80 complex is recruited to DSB by interaction with $\gamma-\mathrm{H} 2 \mathrm{~A}$, perhaps via its Nhp10p and Arp4p subunits, and the Arp8p subunit influences the rate of Rad51p loading at breaks, possibly promoting nucleosome displacement (Sarkar et al., 2010). On the other hand, the INO80 complex may act as a nucleosome acceptor during remodeling for repair, either by temporarily sequestering the displaced nucleosomes or by stabilizing nucleosomes changed during repair and cooperating with other assembly factors to restore chromatin structure after the conclusion of repair (Sarkar et al., 2010).

Mutants of the Arp subunits in the $S$. cerevisiae INO80 complex have defects in NHEJ, as well as in the HR pathway (Morrison and Shen, 2009). Recently, Sarkar et al (2010) have shown that the INO80 complex operates in the same way as the NER pathway, also contributing to the removal of UV photoproducts in the regions of high incidence of nucleosomes. In addition, these authors also reported that the INO80 complex interacts with the Rad4p$\operatorname{Rad} 23 p$ complex, a damage recognition complex of the NER pathway, after its recruitment to chromatin by Rad4p in a UV damage-dependent manner. After DNA damage response activation, the INO80 complex is phosphorylated at its Ies4p subunit, by ataxia-telangiectasia mutated (ATM) and A-T and RAD3-related (ATR) kinases, and it modulates the cellular response to DNA-damaging agents. The Ies4 $p$ subunit is also phosphorylated by the Tellp and Mec1p kinases, modulating DNA replication checkpoint responses without altering DSB repair processes (Morrison and Shen, 2009).

Curiously, Czaja et al. (2010) reported that ino804 yeast mutants are hypersensitive to DNA lesions induced by ultraviolet (UV) radiation and methyl methanesulfonate (MMS), but are less sensitive to the DNA double-strand break (DSB)-inducing agents ionizing radiation and camptothecin. These data suggest that INO80 is involved in DNA damage tolerance through a role in the stabilization and recovery of broken replication forks, but not in the repair of lesions leading to such events. In addition, only 5\% of the genes induced by 8-MOP+UVA treatment are also affected in ino80 8 mutants, showing that INO80 does not appear to regulate the HR pathway at the transcriptional level. Rather it may influence the NHEJ pathway, which is believed to play a modest role in the repair of the photo adducts and DSBs that indirectly result from 8-MOP+UVA treatment (Dardalhon et al., 2007). Furthermore, this study 
also found an unexpected correlation between the transcriptional profiles caused by 8 -MOP+UVA treatment and histone $\mathrm{H} 4$ depletion, with about $62 \%$ of 8 -MOP+UVA response genes also being affected by the lack of this histone.

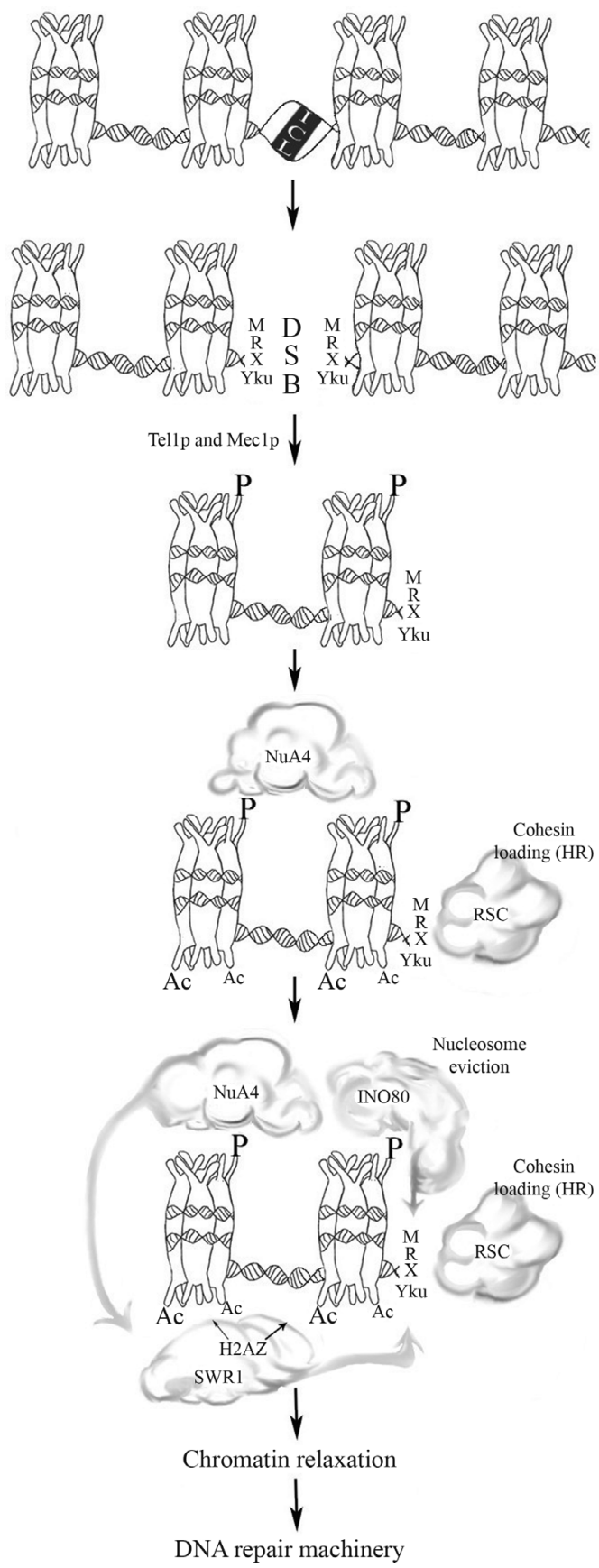

Figure 3 - Main factors involved in chromatin remodeling after 8MOP+UVA induced DNA damage. After ICL incision, MRX complex and Yku-proteins bind to DSB. RSC complex interacts with Mre11p, promoting loading of cohesin at DSB site. The kinases Tellp and Mec1p are recruited and phosphorylate the histone $\mathrm{H} 2 \mathrm{AX}$. The $\gamma$-H2AX recruits NuA4 HAT complex that acetylates $\mathrm{H} 2 \mathrm{AX}$ and $\mathrm{H} 4$ tails, promoting the binding of SWR1 complex that exchange $\gamma$-H2AX with H2AZ. The INO80 complex interacts with $\gamma-\mathrm{H} 2 \mathrm{AX}$ and alters the position of nucleosomes, facilitating the MRX-dependent formation of single-stranded DNA. For more details, see the text.
About $15 \%$ of the genes affected after 8 -MOP+UVA treatment in yeast are also modulated in $\operatorname{swr} 1 \Delta, h t z 1 \Delta$ and $\operatorname{sir} 2 \Delta$ cells, suggesting that the replacement of histone $\mathrm{H} 2 \mathrm{~A}$ with $\mathrm{H} 2 . \mathrm{Z}$ in nucleosomes, as well as a Sir contribution to telomeric silencing, may influence the repair of 8MOP+UVA induced damage (Dardalhon et al., 2007). The biology of SWR1 and Htz1 has been intensely studied for their roles in transcriptional regulation. SWR1 also acts in DSB repair in an independent manner, controlling the $\gamma$ H2A levels at DSB sites (Osley et al., 2007; Escargueil et al., 2008). In yeast strains lacking Htz1, the SWR1 complex promotes an accumulation of recombinogenic DNA damage by a mechanism dependent on $\gamma-\mathrm{H} 2 \mathrm{~A}$, suggesting that the SWR1 complex hinders the repair of spontaneous DNA damage in these mutants (Morillo-Huesca et al. 2010). In addition, the inactivation of Swr1p eliminates the incorporation of histone variant Htzl and restores the phosphorylation of H2A and checkpoint adaptation (Papamichos-Chronakis et al., 2006). The replacement of H2A with Htzl is an essential mechanism for the control of chromatin dynamics, and also prevents the deleterious consequences of incomplete nucleosome remodeling (Morillo-Huesca et al., 2010).

Mutations in the yeast RSC chromatin remodeling complex (Table 1) cause hypersensitivity to DNA breakinducing agents (van Attikum and Gasser, 2005a). RSC has homologs in other eukaryotes and acts in transcriptional activation and repression, maintenance of cell viability and in DSB repair (Osley et al., 2007). The RSC complex subunit Rsc8p and the catalytic subunit Sth1p are recruited to DSBs, where the latter rapidly binds to the lesion and accumulates in regions immediately adjacent to the damage (van Attikum and Gasser, 2005b). Defects in RSC complex activity cause hypersensitivity to DSBs, which can be attributed to defects in NHEJ and HR repair pathways. Furthermore, the RSC complex is recruited to the DSB break at the same time as the MRX (Mre11p/Rad50p/Xrs2p) complex (Figure 3), involved in NHEJ, HR and checkpoint signaling, both of which can lead to remodeling of chromatin near the break site and facilitate the access of NHEJ factors (Osley et al., 2007). The RSC complex can also load cohesin onto chromosome arms, maintaining the sister chromatids close, and during DSB repair it may promote the binding of proximal ends during NHEJ and of distal ends during HR (Osley et al., 2007). The importance of this cohesin loading reflects the fact that defects in the establishment of cohesion during S-phase or de novo loading of cohesin at DSBs in the $\mathrm{G}_{2}$ phase reduce the efficiency of post-replication repair (PRR) (van Attikum and Gasser, 2005a).

The histone methyltransferase Dot1p is responsible for methylation of histone $\mathrm{H} 3$ on lysine 79 , and this process is dependent on the ubiquitylation of $\mathrm{H} 2 \mathrm{~B}$ lysine 123 by Rad6p-Bre1p (Giannattasio et al., 2005). It is possible that these reactions work together, activating checkpoint re- 
sponses to DNA damage (van Attikum and Gasser, 2005b). The activity of Dot1p also prevents DSB repair of meiotic cells in the absence of Dmc1p, using the sister chromatid as a template (San-Segundo and Roeder, 2000). Dotlp also acts in the DNA damage response by activating Rad53p. This is mediated by Rad9p during the $\mathrm{G}_{1} / \mathrm{S}$ and intra-S DNA damage checkpoints (Conde et al., 2009). In this scenario, Cardone et al. (2006) proposed a model for yeast checkpoint activation after 8-MOP+UVA treatment in which the checkpoint is activated by means of Rad9p phosphorylation in a process dependent on the recruitment of the $\operatorname{Ddc} 1 \mathrm{p} / \mathrm{Mec} 3 \mathrm{p} / \mathrm{Rad} 17 \mathrm{p}$ complex. The latter can regulate Chk1p and Rad53p, suggesting that PSO9/MEC3 is crucial for sensing DNA lesions generated by photo-induced psoralens or other mutagens. A recent study suggests that histone $\mathrm{H} 3$ methylation and Rad9p act together, enabling transmission of the damage signal to checkpoint kinases and keeping resection of damaged DNA under control (Lazzaro et al. 2008). This would affect checkpoint cascades and contribute to the DNA damage response. Interestingly, the $\operatorname{dot} 1 \Delta$ mutant shows increased resistance to the alkylating agent MMS. Accordingly, the reduced sensitivity of some mutants deficient in DNA repair has also been attributed to an increase in TLS repair pathway activity in the absence of Dot1p (Conde and San-Segundo, 2008).

A recent study by Faucher and Wellinger (2010) shows that monoubiquitylation of histone $\mathrm{H} 2 \mathrm{~B}$ and trimethylation of histone $\mathrm{H} 3$ at lysin 4 ( $\mathrm{H} 3 \mathrm{~K} 4 \mathrm{me} 3)$ are important for both the response to DNA damaging agents and the passage through S-phase in budding yeast. The recruitment of the methyltransferase Set1p to the DSB is dependent on the presence of the RSC complex, thus contributing to DNA damage repair. In this context, yeast mutants lacking Set1p show impaired ability to recruit the Yku-proteins to DSB sites, leading to reduced efficiency of the NHEJ pathway. In addition, H2BK123ub is also required for H3K79 methylation by Dot1p. The loss of NHEJ-efficiency and the synthetic interactions with MRX are specific to a lack of H3K4me3 and not H3K79me3, showing that the roles of Set $1 \mathrm{p}$ in genome stability are different from those of Dot $1 \mathrm{p}$ methyltransferase.

The analysis of global transcriptional responses after treatment with $8-\mathrm{MOP}+\mathrm{UVA}$ in yeast shows that $25 \%$ of the genes modified by this treatment were also changed in snf2 and/or swil deletion mutants, indicating that the $S$. cerevisiae SWI/SNF complex is implicated in gene expression following 8-MOP+UVA exposure (Dardalhon et al., 2007). The yeast SWI/SNF complex acts in gene transcription and DSB repair (Osley et al., 2007). SWI/SNF increases accessibility to DNA in the nucleosome core, even though the NER repair proteins also increase their remodeling activity. This suggests a cooperative relationship between DNA damage repair and chromatin remodeling. The chromatin remodeling activity of the SWI/SNF complex changes the histone-DNA contacts, slides or remodels nucleosomes or transfers histone dimers in vitro (Osley et al., 2007). Yeast mutants lacking SWI/SNF activity are sensitive to DNA damage agents that cause DSBs, and there is strong evidence that suggests the role of this complex in the HR repair pathway.

The up-regulation of the genes RAD51, RAD54, $R N R 2, R N R 4, D I N 7$ and $R N R 3$ in response to treatment with 8-MOP+UVA, MMS and ionizing radiation (Dardalhon et al., 2007) is also consistent with the importance of recombination pathways in the repair of ICLs. Rad54 protein and its homolog Rdh54p in S. cerevisiae are present in yeast and higher eukaryotes. They belong to the Swi/Snf family of ATPase chromatin remodeling factors. In vitro, Rdh54p acts like Rad54p, promoting Rad51p D-loop formation through the induction of negative supercoiling of the DNA duplex. The product of the RDH54 gene acts in the control of damage repair and Rdh54p is involved in the regulation of many DNA repair pathways like BER, NER or recombinational and mutagenic repair pathways. This function is possibly mediated by changes in chromatin structure in DNA damage sites, probably by alleviation of DNA-histone bonds, making the DNA accessible to the repair proteins (Latypov et al., 2010).

\section{Final Considerations}

DNA repair is a critical cellular function that maintains genomic stability and prevents mutations. Current data support the i.e. that histone modifications are essential for cell survival in response to DNA damage through induction of cell cycle checkpoints and DNA repair. The interstrand crosslinks formed by 8-MOP+UVA are highly detrimental lesions that are too complex to be processed by a single repair pathway. The existing data show the involvement of NER, BER, TLS and double-strand break repair (HR and NHEJ) in ICL processing. As described above, the repair of 8-MOP+UVA lesions in Saccharomyces cerevisiae can result in the transient formation of DSBs, and both NER and a Pso2p/Msh2p/Exolp-dependent pathway are required to process ICLs in S-phase cells prior to DSB repair. Moreover, 8-MOP+UVA treatment leads to up-regulation of genes related to cell cycle regulation and repression of genes related to chromatin remodeling, which is consistent with changes in chromatin structure relevant to DNA repair. Taken together, these findings indicate a specific profile of 8-MOP+UVA responses related to chromatin remodeling and DNA repair. Further studies are certainly required to clarify the relationships between the DNA damage response to psoralen, cell cycle checkpoint induction and chromatin remodeling.

\section{Acknowledgments}

This work was supported by Fundação de Amparo à Pesquisa do Rio Grande do Sul - FAPERGS, Conselho 
Nacional de Desenvolvimento Científico e Tecnológico (CNPq), Programa de Apoio a Núcleos de Excelência (PRONEX/ FAPERGS/ CNPq10/0044-3) and Coordenação de Aperfeiçoamento de Pessoal de Ensino Superior (CAPES).

\section{References}

Altaf M, Saksouk N and Côté J (2007) Histone modifications in response to DNA damage. Mutat Res 618:81-90.

Ataian Y and Krebs JE (2006) Five repair pathways in one context: Chromatin modification during DNA repair. Biochem Cell Biol 84:490-504.

Bonatto D, Revers LF, Brendel M and Henriques JAP (2005) The eukaryotic Pso2/Snm1/Artemis proteins and their function as genomic and cellular caretakers. Braz J Med Biol Res 38:321-334.

Brendel M, Bonatto D, Strauss M, Revers LF, Pungartnik C, Saffi J and Henriques JAP (2003) Role of PSO genes in repair of DNA damage of Saccharomyces cerevisiae. Mutat Res 544:179-193.

Brendel M and Henriques JAP (2001) The pso mutants of Saccharomyces cerevisiae comprise two groups: One deficient in DNA repair and another with altered mutagen metabolism. Mutat Res 489:79-96.

Le Breton C, Hennion M, Arimondo PB and Hyrien O (2011) Replication-fork stalling and processing at a wingle psoralen interstrand crosslink in Xenopus egg extracts. PLoS One 6:e18554

Cardone JM, Revers LF, Machado RM, Bonatto D, Brendel M and Henriques JAP (2006) Psoralen-sensitive mutant pso9-1 of Saccharomyces cerevisiae contains a mutant allele of the DNA damage checkpoint gene MEC3. DNA Repair 5:163171.

Cattell E, Sengerová B and McHugh P (2010) The SNM1/Pso2 family of ICL repair nucleases: From yeast to man. Environ Mol Mutagen 51:635-645.

Celeste A, Fernandez-Capetillo O, Kruhlak MJ, Pilch DR, Staudt DW, Lee A, Bonner RF, Bonner WM and Nussenzweig A (2003) Histone H2AX phosphorylation is dispensable for the initial recognition of DNA breaks. Nat Cell Biol 5:675679.

Celeste A, Petersen S, Romanienko PJ, Fernandez-Capetillo O, Chen HT, Sedelnikova OA, Reina-San-Martin B, Coppola V, Meffre E, DiFilippAntonio MJ, et al. (2002) Genomic instability in mice lacking histone H2AX. Science 296:922927.

Conde F and San-Segundo P (2008) Role of Dot1 in the response to alkylating DNA damage in Saccharomyces cerevisiae: Regulation of DNA damage tolerance by the error-prone polymerases Polzeta/Rev1. Genetics 179:1197-210.

Conde F, Refolio E, Cordón-Preciado V, Cortés-Ledesma F, Aragón L, Aguilera A and San-Segundo P (2009) The Dot1 histone methyltransferase and the Rad9 checkpoint adaptor contribute to cohesin-dependent double-strand break repair by sister chromatid recombination in Saccharomyces cerevisiae. Genetics 182:437-446.

Czaja W, Bespalov VA, Hinz JM and Smerdon MJ (2010) Proficient repair in chromatin remodeling defective ino80 mutants of Saccharomyces cerevisiae highlights replication de- fects as the main contributor to DNA damage sensitivity. DNA Repair 9:976-84.

Dardalhon M, de Massy B, Nicolas A and Averbeck D (1998) Mitotic recombination and localized DNA double-strand breaks are induced after 8-methoxypsoralen and UVA irradiation in Saccharomyces cerevisiae. Curr Genet 34:30-42.

Dardalhon M, Lin W, Nicolas A and Averbeck D (2007) Specific transcriptional responses induced by 8-methoxypsoralen and UVA in yeast. FEMS Yeast Res 7:866-878.

Dudás A, Vlasáková D, Dudásová Z, Gabcová D, Brozmanová J and Chovanec M (2007) Further characterization of the role of Pso2 in the repair of DNA interstrand cross-link-associated double-strand breaks in Saccharomyces cerevisiae. Neoplasma 54:189-194.

Escargueil A, Soares DG, Salvador M, Larsen AK and Henriques JAP (2008) What histone code for DNA repair? Mutat Res 658:259-270.

Faucher D and Wellinger RJ (2010) Methylated H3K4, a transcription-associated histone modification, is involved in the DNA damage response pathway. PLoS Genetics 6:e1001082.

Gangaraju VK and Bartholomew B (2007) Mechanisms of ATP dependent chromatin remodeling. Mutat Res 618:3-17.

Giannattasio M, Lazzaro F, Plevani P and Muzi-Falconi M (2005) The DNA damage checkpoint response requires histone H2B ubiquitination by Rad6-Bre1 and $\mathrm{H} 3$ methylation by Dot1. J Biol Chem 280:9879-9886.

Guainazzi A and Schärer OD (2010) Using synthetic DNA interstrand crosslinks to elucidate repair pathways and identify new therapeutic targets for cancer chemotherapy. Cell Mol Life Sci 67:3683-3697.

Hazrati A, Ramis-Castelltort M, Sarkar S, Barber LJ, Schofield J, Hartley J A and McHugh PJ (2008) Human SNM1A suppresses the DNA repair defects of yeast pso2 mutants. DNA Repair 7:230-238.

Hejna J, Philip S, Ott J, Faulkner C and Moses R (2007) The hSNM1 protein is a DNA 5'-exonuclease. Nucleic Acids Res 35:6115-6123.

Henriques JAP, Brozmanova J and Brendel M (1997) Role of PSO genes in the repair of photoinduced interstrand crosslinks and photooxidative damage in the DNA of the yeast Saccharomyces cerevisiae. J Photochem Photobiol 39:185196.

Henriques JAP and Moustacchi E (1980) Isolation and characterization of pso mutants sensitive to photo-addition of psoralen derivatives in Saccharomyces cerevisiae. Genetics 95:273-288.

Henriques JAP and Moustacchi E (1981) Interactions between mutations for sensitivity to psoralen photoaddition (pso) and to radiation (rad) in Saccharomyces cerevisiae J Bacteriol 148:248-256.

Latypov VF, Kozhina TN, Kozhin S and Korolev VG (2010) The role of the Rdh54 protein in regulation of DNA repair in yeast Saccharomyces cerevisiae. Russ J Genet 46:170-177.

Lazzaro F, Sapountzi V, Granata M, Pellicioli A, Vaze M, Haber JE, Plevani P, Lydall D and Muzi-Falconi M (2008) Histone methyltransferase Dot1 and Rad9 inhibit single-stranded DNA accumulation at DSBs and uncapped telomeres. EMBO J 27 :1502-1512. 
Lehoczky P, McHugh PJ and Chovanec M (2007) DNA interstrand cross-link repair in Saccharomyces cerevisiae. FEMS Microbiol Rev 31:109-133.

Lobrich M and Jeggo PA (2007) The impact of a negligent G2/M checkpoint on genomic instability and cancer induction. Nat Rev Cancer 7:861-869.

Lu PYT, Levesque N and Kobor MS (2009) NuA4 and SWR1-C: Two chromatin-modifying complexes with overlapping functions and components. Biochem Cell Biol 87:799-815.

Lucchini R and Wellinger RE (2001) Nucleosome positioning at the replication fork. EMBO J20:7294-7302.

Macé-Aimé G, Couvé S, Khassenov B, Rosselli F and Saparbaev MK (2010) The Fanconi anemia pathway promotes DNA glycosylase-dependent excision of interstrand DNA crosslinks. Environ Mol Mutagen 51:508-519.

Magaña-Schwencke N, Henriques JAP, Chanet R and Moustacchi E (1982) The fate of 8-methoxypsoralen photoinduced crosslinks in nuclear and mitochondrial yeast DNA: Comparison of wild-type and repair-deficient strains. Proc Natl Acad Sci USA 79:1722-1726.

Morillo-Huesca M, Clemente-Ruiz M, Andújar E and Prado F (2010) The SWR1 histone replacement complex causes genetic instability and genome-wide transcription misregulation in the absence of H2A.Z. PloS One 5:e12143.

Morrison AJ and Shen X (2009) Chromatin remodelling beyond transcription: The INO80 and SWR1 complexes. Nature reviews. Molecular Cell Biology 10:373-384.

Noll DM, Mason TM and Miller PS (2006) Formation and repair of interstrand cross-links in DNA. Chem Rev 106:277-301.

Osley MA, Tsukuda T and Nickoloff JA (2007) ATP-dependent chromatin remodeling factors and DNA damage repair. Mut Res 618:65-80.

Papamichos-Chronakis M, Krebs JE and Peterson CL (2006) Interplay between Ino80 and Swr1 chromatin remodeling enzymes regulates cell cycle checkpoint adaptation in response to DNA damage. Genes Dev 20:2437-2449.

Saffran WA, Ahmed S, Bellevue S, Pereira G, Patrick T, Sanchez W, Thomas S, Alberti M and Hearst JE (2004) DNA repair defects channel interstrand DNA cross-links into alternate recombinational and error-prone repair pathways. J Biol Chem 279:36462-36469.
San-Segundo PA and Roeder GS (2000) Role for the silencing protein Dot1 in meiotic checkpoint control. Mol Biol Cell 11:3601-3615.

Sarkar S, Davies A, Ulrich HD and McHugh PJ (2006) DNA interstrand crosslink repair during G1 involves nucleotide excision repair and DNA polymerase zeta. EMBO J 25:1285-1294.

Sarkar S, Kiely R and McHugh PJ (2010) The Ino80 chromatinremodeling complex restores chromatin structure during UV DNA damage repair. J Cell Biol 191:1061-1068.

Sweeney FD, Yang F, Chi A, Shabanowitz J, Hunt DF and Durocher D (2005) Saccharomyces cerevisiae $\operatorname{Rad} 9$ ats as a Mec1 adaptor to allow Rad53 activation. Curr Biol 15:1364-1375.

van Attikum H and Gasser SM (2005a) The histone code at DNA breaks: A guide to repair? Nat Rev Mol Cell Biol 6:757-765.

van Attikum H and Gasser SM (2005b) ATP-dependent chromatin remodeling and DNA double-strand break repair. Cell Cycle 4:1011-1014.

van Attikum H and Gasser SM (2009) Crosstalk between histone modifications during the DNA damage response. Trends Cell Biol 19:207-217.

Vasquez KM (2010) Targeting and processing of site-specific DNA interstrand crosslinks. Environ Mol Mutagen 51:527539.

Wang AY, Schulze JM, Skordalakes E, Gin JW, Berger JM, Rine J and Kobor MS (2009) Asfl-like structure of the conserved Yaf9 YEATS domain and role in H2A.Z deposition and acetylation. Proc Natl Acad Sci USA 106:21573-21578.

Wood RD (2010) Mammalian nucleotide excision repair proteins and interstrand crosslink repair. Environ Mol Mutagen 51:520-526.

Yan D, Ng WL, Zhang X, Wang P, Zhang Z, Mo Y-Y, Mao H, Hao C, Olson JJ, Curran WJ, et al. (2010) Targeting DNAPKcs and ATM with miR-101 sensitizes tumors to radiation. PLoS One 5:e11397.

Yuan J and Chen J (2010) MRE11-RAD50-NBS1 complex dictates DNA repair independent of H2AX. J Biol Chem 285:1097-1104.

License information: This is an open-access article distributed under the terms of the Creative Commons Attribution License, which permits unrestricted use, distribution, and reproduction in any medium, provided the original work is properly cited. 